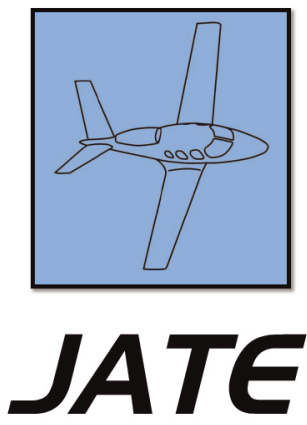

Journal of Aviation Technology and Engineering 1:2 (2012) 74-78

DOI: $10.5703 / 1288284314660$

\title{
Lead Memory in General Aviation Aircraft Engine Emissions
}

\section{Randal DeMik, Jason Keleher, Natalie Kasak, Julius Keller, Alessandro Mazza, and Jordan Raess}

Lewis University

\begin{abstract}
There is interest from environmental organizations and regulating agencies to eliminate lead and reduce pollutants emitted into the atmosphere from general aviation aircraft using 100LL aviation gasoline (Avgas). 100SF (Swift Fuel) is under development by Swift Enterprises as a lead free general aviation alternative fuel product. The purpose of this study is to determine the amount of time required for engines to be free of lead emissions when first introduced to operation using 100SF. This study also investigated the lead cleansing decay profiles of the aircraft engines under 100SF initial operations. Results of this study revealed that a mean engine run time of 21 minutes and 20 seconds was needed before aircraft engines were free of measurable lead at a $15 \mathrm{ppm}$ limit of detection. Results lend support for 100SF as a lead free alternative fuel source that also acts as a lead cleanser for general aviation aircraft engines.
\end{abstract}

Keywords: Avgas, unleaded gasoline, alternative fuels, lead memory, emissions

\section{Introduction}

Representatives of the aviation community are interested in developing lead-free alternatives to conventional gasoline used for general aviation aircraft piston engine operations. This segment of general aviation aircraft uses aviation gasoline (avgas) that is designated as 100 Low Lead (100LL). According to Schaufele (2008), there are more than 200,000 general

\section{About the Authors}

Randal J. DeMik is an associate professor in aviation and transportation studies at Lewis University. He earned his Ph.D. in technology management from Indiana State University in 2008. Dr. DeMik is a captain and line check airman with United Airlines and an FAA certificated flight instructor.

Jason J. Keleher is an assistant professor in chemistry at Lewis University. He earned his Ph.D. in organic chemistry/materials from Clarkson University in 2004. Dr. Keleher also worked for Cabot Microelectronics Corporation as a senior research scientist.

Natalie A. Kasak is a graduate student in aviation and transportation studies at Lewis University. Ms. Kasak is an FAA certified flight instructor.

Julius C. Keller is a graduate student in aviation and transportation studies at Lewis University. Mr. Keller is an FAA certified flight instructor.

Alessandro R. Mazza is an undergraduate student in chemistry at Lewis University.

Jordan R. Raess is a graduate student in aviation and transportation studies at Lewis University. Mr. Raess is a critical infrastructure analyst at Argonne National Laboratory. 
This research was sponsored, in part, by a grant from The Colonel Stephan S. And Lyla Doherty Center for Aviation and Health Research. The authors would like to thank Ron Adams of Swift Enterprises, Bill Wetstein and Paul Smith (A\&P technicians) of Lewis University Aviation, and Jon Palek of EMS-Gas for their helpful technical assistance.

aviation aircraft that burn approximately 190 million gallons of 100LL annually. This exhaust makes up 45\% of the total lead emissions in the air over the United States.

Early automotive engineers discovered that gasoline has a tendency to "knock;" that is, explode rapidly instead of burning smoothly inside engine cylinders. According to Midgley (1937), knocking was eliminated when the chemical compound tetra-ethyl lead (TEL) was added to gasoline. The discovery of leaded fuel allowed for the development of powerful, high compression engines.

As leaded fuel was found to be very effective in high compression engines, its use spread from the automotive to the aviation industry. After the automotive revolution, aircraft engine manufacturers produced military aircraft with high performance engines designed to run on leaded fuel for use in World War II. High performance piston-engine aircraft used in WWII required lead additives in gasoline to prevent detonation, which has been shown to cause engine damage (Harvey, 2006). Detonation causes a large pressure spike in the combustion chamber (Cline, 2000). After the war, aircraft engine manufacturers continued to produce aircraft engines that use leaded fuel.

While leaded fuel aids in the prevention of knocking and detonation, it also has negative side effects in the form of engine operation and performance issues. According to AeroShell (2011), when TEL burns it degrades to lead oxide which remains in solid form under normal operating temperatures. When an engine operates at lower temperatures, such as during taxi and low-power descents or with an excessively rich mixture, it is susceptible to lead buildup. Windom, Lovestead, and Bruno (2010) found that lead accumulation inside the engine may cause spark plug fouling, valve and piston ring sticking, and cylinder wall glazing. Furthermore, lead deposits are electrically conductive and corrosive, meaning they have the ability to short out spark plugs and erode the metal parts and valves inside the engine (AeroShell, 2011).

When TEL was first added to fuel, there was no information about the negative health consequences of lead exposure. According to the Agency for Toxic Substances \& Disease Registry (ATSDR) of the U.S. Department of Health and Human Services, lead can affect every organ in the human body. Exposure to high levels of lead can damage the brain, kidneys, and nervous system. Children are more vulnerable to lead poisoning, and even small amounts of lead ingestion can impair their mental and physical growth (U.S. Department of Health and Human Services, 2007). Lead is not only harmful to humans, but wildlife as well. Predators accumulate higher pollutant concentrations than their contaminated prey. As a result, people and other animals at the top of the food chain that consume contaminated fish or meat are exposed to higher concentrations of lead than the concentrations in the water, air, or soil (Environmental Protection Agency, 2011). Recognition of TEL as a toxic substance has guided the phase-out of leaded gasoline in automobiles that began in 1970 in the United States (Matsui, 2007).

Currently, piston-engine-equipped general aviation aircraft still use leaded fuel. The EPA estimates that between 1970 and 2007, the combustion of avgas in general aviation has released 34,000 tons of lead into the atmosphere and affects three million children who attend school near aviation facilities (Environmental Protection Agency, 2010). The EPA has issued an advance notice of proposed rulemaking (ANPR) addressing engine emission standards for piston aircraft. Awareness of the negative health and environmental consequences of leaded fuel and the recent ANPR are prompting research towards an unleaded alternative to avgas.

Research and development in the area of a specific high octane alternative to leaded fuel for general aviation is being conducted by Swift Enterprises. Established in 2001 and centered in the Purdue Research Park, Swift Enterprises offers a possible solution through developing a less toxic fuel to be used in general aviation aircraft, 100SF (Swift Fuel). Since the fuel is synthesized from simple biomass, this renewable fuel source has less of an impact on the environment in both its creation and its use (Sargent, 2008). While it contains no TEL, 100SF has a motor octane number (MON) of 104, which would provide slightly better detonation performance than 100LL for use in high performance aircraft engines. In a study by Atwood (2009) it was found that engines burning 100SF produced approximately $98 \%$ as much power as they did when using 100LL. Swift Fuel contained 96.3\% of the energy content per unit mass as the 100LL. On a volume basis, Swift fuel contained 13\% more energy than 100LL. Swift fuel also resulted in an average decrease in volumetric fuel consumption of approximately $8 \%$. Due to the composition of 100SF, it has been proposed that 100SF would act as a "cleanser" of the engines. Burning cleaner than 100LL, it was thought that residual lead in aircraft engines from years of use (lead memory) of 100LL would be released while burning 100SF.

\section{Statement of the Problem}

To reduce lead emissions released by general aviation aircraft engines, Swift Enterprises proposed 100SF as a possible replacement for current 100LL fuel used today. Therefore, this study investigated two areas: whether a sampling of general 
aviation aircraft engines could produce a relationship between the times to reach no measurable amounts of lead emissions, and what the lead cleansing characteristics would be while using 100SF. The study attempted to answer the following specific research questions:

1. When operating general aviation aircraft engines at high idle power (1200 RPM), how many minutes will it take until the sampling of engines is free of measurable lead within a $15 \mathrm{ppm}$ limit of detection?

2. When general aviation aircraft engines are first introduced to 100SF operations, what are the lead cleansing pattern behaviors and characteristics regarding concentration of lead within emissions as a function of time?

\section{Methodology}

\section{Engines}

The following common general aviation engine types were available for use in this study: the Lycoming IO-360 (fuel injected, 200hp), O-235 (115hp), O-290 (135hp) and Continental O-200 (100hp). These engines are installed in popular general aviation aircraft across the globe and provide a sample of engines that is common among the population of general aviation engines. All engines included in this study had been operated for multiple years and thousands of hours using 100LL fuel. Prior to testing, each engine was drained of 100LL from fuel tanks and fuel lines.

\section{Measures}

The engines ${ }^{1}$ that were selected were a Lycoming IO360 200hp, Lycoming O-235 115hp, and a Lycoming O290 135hp. An Emissions Systems, Inc. EMS Model 5001 Portable Exhaust Gas Analyzer was also utilized in this study to collect the lead emission samples. A small hole for probe insertion was drilled in each engine's exhaust pipe. A 25 foot long hose conveyed the exhaust from the probe to the EMS emissions analyzer, and the unit's graphing software displayed the results. A cotton swab was placed in the exhaust line prior to the point where the exhaust reached the analyzer to capture the lead particulates being released from the engines.

\section{Procedures}

Samples were collected directly from the tailpipe of each of the engines using the EMS analyzer as a vacuum to pull the tailpipe lead and emissions through a cotton swab.

\footnotetext{
${ }^{1}$ A fourth engine was used during testing, a Continental O-200 (100hp). The Continental O-200 engine suffered an oil leak and was removed from the study.
}

These emissions were pulled from both tailpipes of the IO360 and the O-235. In the case of the O-290, the engine has only one tailpipe; thus, the test was run with two probes in the single tailpipe. During the testing, the engine was run at a high idle power (between idle and cruise powers) for about 30 minutes using 100SF. Every two minutes a cotton swab was pulled and replaced for the 15 consecutive samples.

The lead samples collected were first weighed and dissolved in $3 \mathrm{M}$ nitric acid (HNO3) overnight. The following day a complexation titration using Ethylenediaminetetraacetic acid (EDTA), Eriochrome black $\mathrm{T}$ indicator, and a $\mathrm{pH} 10$ ammonia buffer was performed to determine the amount of lead in milligrams ( $\mathrm{mg}$ ) per gram (g) of sample collected. EDTA complexes with the lead ion in solution and, when all of the lead is complexed the excess EDTA creates a clear endpoint by interaction with the indicator, Eriochrome black T. This endpoint is signaled by the change in color from purple to blue. The results of the titration were normalized by dividing the lead content of the cotton swab by the total weight of the sample (Loyola University of Chicago, 2011).

\section{Results}

The first research question was constructed to determine the amount of engine run time required for emissions to be free of lead within a detection limit of $15 \mathrm{ppm}$. From each engine, samples were extracted from the exhaust pipes every two minutes during the 30 minute initial engine run time with 100SF. Each engine's 15 samples were then analyzed as described in the procedures section.

The Lycoming O-235 released traceable amounts of lead until 22 minutes (refer to Figure 1). The Lycoming O-290 engine also released traceable amounts of lead until 22

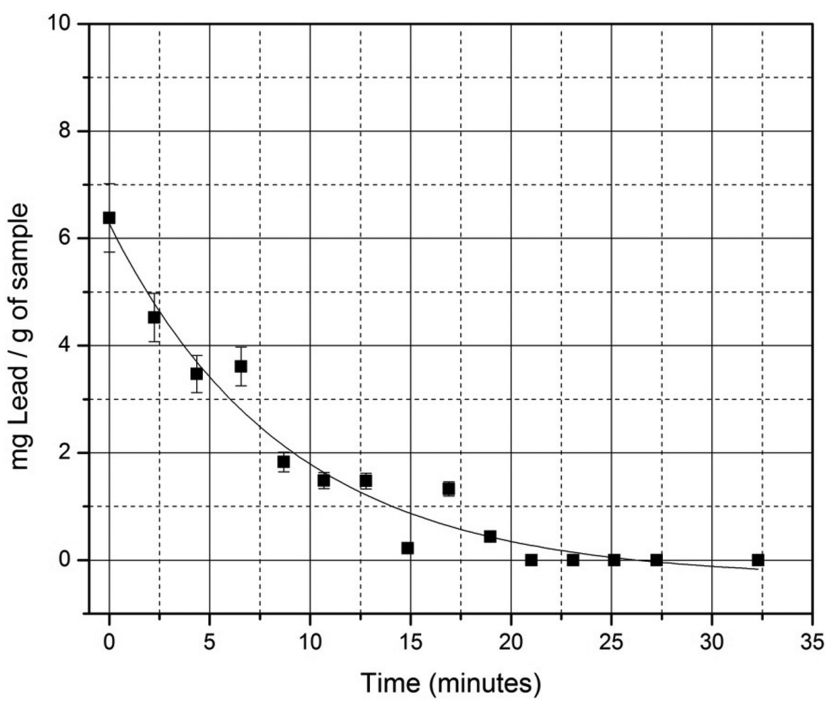

Figure 1. Lycoming O-235 lead memory 


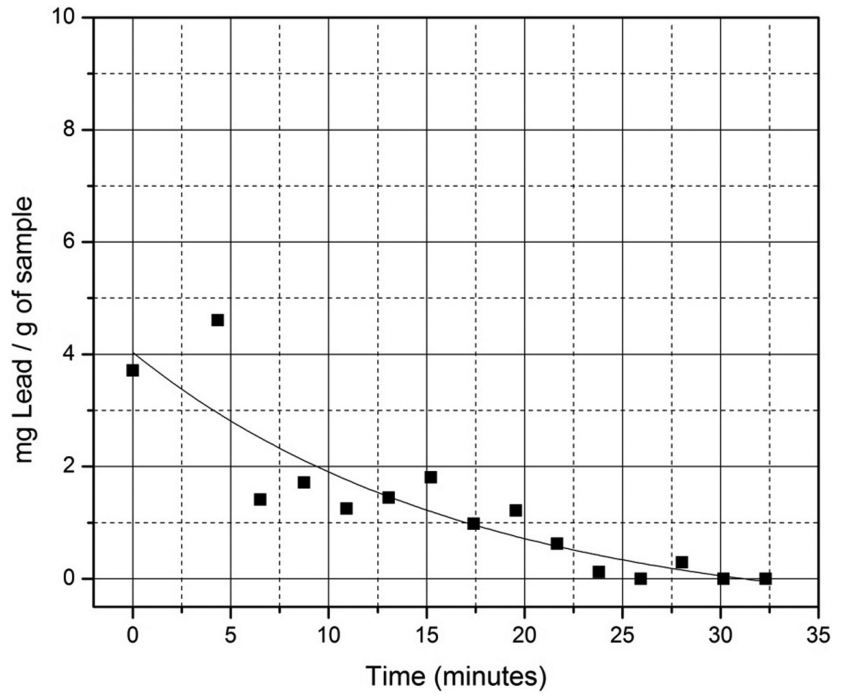

Figure 2. Lycoming O-290 lead memory

minutes (refer to Figure 2). However, the Lycoming IO360 released traceable amounts of lead until 20 minutes (refer to Figure 3). For the three engines used in the study, a mean time of 21 minutes and 20 seconds was needed to cleanse the engines of lead emissions $(m=21: 20, s d=$ $0: 34)$.

The second research question was constructed to determine lead cleansing pattern behaviors and characteristics when engines that have been operated with 100LL are first introduced to 100SF. Apparent nonlinearity in the experimental data required the use of an exponential decay function to determine the concentration of lead emissions as a function of time. Equation 1 gives the exponential function that was used for analysis:

$$
y=A \cdot e^{-k\left(x-x_{0}\right)}
$$

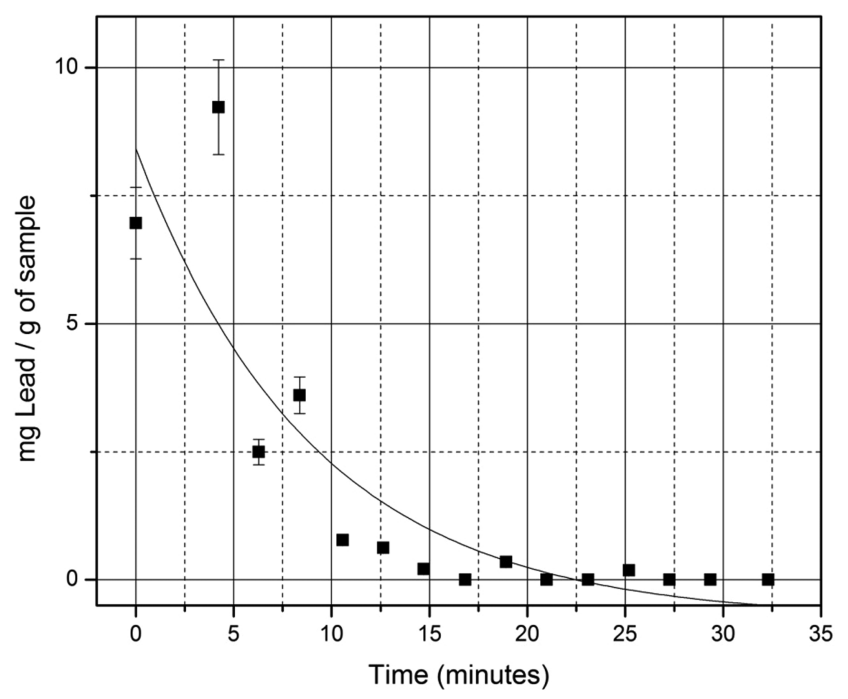

Figure 3. Lycoming IO-360 lead memory
Table 1

Lead Memory Results

\begin{tabular}{lcl}
\hline Engine & Slope $(\mathbf{k})$ & $\mathbf{R}^{\mathbf{2}}$ \\
\hline Lycoming 0-235 & .113 & .953 \\
Lycoming 0-290 & .059 & .736 \\
Lycoming IO-360 & .111 & .702 \\
\hline
\end{tabular}

The examination of the data reveals that lead concentrations in each engine decayed exponentially (as shown in Table 1) and at different rates as shown by comparing the slopes of the trend lines in figures 1-3.

When analyzing the exponential decay of lead emissions, the researchers found that the slopes (i.e., rates) of exponential decay were $\mathrm{k}=.113$ for the Lycoming O235 and $\mathrm{k}=.111$ for the Lycoming IO-360. While the Lycoming O-290 $(\mathrm{k}=.059)$ had a decreased slope, the lead emissions also showed an exponential decay (Figure 2). The exponential decay functions that were found for the engines tested indicate an $\mathrm{R}^{2}$ value of .959 for the Lycoming O-235, .736 for the Lycoming O-290, and .702 for the Lycoming IO-360.

\section{Discussion of the Results}

The purpose of this lead emissions study was to provide empirical evidence that 100SF fuel reduced lead emissions released by general aviation aircraft engines. The intent of this study was to determine whether a sampling of general aviation aircraft engines has a relationship between the time to reach no measurable amounts of lead emissions and the lead cleansing pattern behaviors and characteristics regarding concentration of lead within emissions as function of time when introducing 100SF. The results of this study indicated that engines using 100SF were free of lead within 22 minutes of engine run time at high idle power. The data also illustrated that each engine had an exponential decay and reached a lead minimum within a comparable amount of time.

Although the engines reached a lead minimum within 22 minutes, the rate at which this was achieved was generally slower for the Lycoming O-290 $(\mathrm{k}=.059)$. There are several confounding factors and plausible explanations for these findings. The Lycoming IO-360 being fuel injected, a higher volume of 100SF was burned by this engine in a shorter time period than in the Lycoming O-290, and this may have affected the slope. This trend is also prevalent when analyzing the oscillating behavior of the data points. The initial data point from the Lycoming IO-360 had a mass of $6.97 \mathrm{mg}$ per $\mathrm{g}$ sample. This was followed by an increase of $2.62 \mathrm{mg}$ per g sample, followed by a prolific drop of $6.74 \mathrm{mg}$ per g sample, a much lesser incline of 1.12 $\mathrm{mg}$ per g sample, and a final drop of $2.82 \mathrm{mg}$ per $\mathrm{g}$ sample before reaching a lead minimum; similar to a simple damped harmonic oscillator. This occurred all within a shorter time period than the Lycoming O-290. The Lycoming O-290 also exhibited oscillating behavior when 
looking at mass change trends. Observance of the graphical information demonstrates this oscillating effect may reflect an initiation and/or dispersal of lead as a function of time and 100SF exposure.

The Lycoming O-235 did not initially behave in this oscillating fashion. This is attributed to an estimate of just fewer than five minutes of initial engine run time that was not included in the data. Unfortunately, the Lycoming $\mathrm{O}-235$ had several unsuccessful start attempts. While trying to start the engine with 100SF, there was some runtime that was not included until the engine finally ran smoothly. Since the Lycoming O-235 did not have the initial two data points recorded, this may be why the $\mathrm{R}^{2}$ value was high, as well as why the data did not exhibit the dramatic initial oscillation effect. The data was included because it still had an exponential decay, thus supporting previously discussed observations.

The findings of the researchers are consistent with Swift Enterprises' assertion that 100SF acts as a "lead-cleanser" fuel source. Although each engine released lead at different rates, this study found that the initial application of 100SF as a fuel source would remove lead emissions within 22 minutes of engine run time at high idle power.

\section{Recommendations for Future Research}

The question of the appropriate replacement fuel for improving aircraft emissions is an area that demands further research. Finding a lead-free aviation fuel that can be used with 100 percent of piston-driven aircraft engines has been a significant challenge. Further work in the area of lead-free alternative fuels has been indicated. While the results of this study indicated that 100SF reduces the lead memory in engines, these engines were not tested during flight. It would be interesting to see how the lead memory and emissions are impacted when using 100SF in engines during flight.

Another area for future research is the comparison of pollutants emitted by 100SF and 100LL, such as carbon monoxide $(\mathrm{CO})$, nitric oxide $(\mathrm{NO})$, nitrogen dioxide $\left(\mathrm{NO}_{2}\right)$ and sulfur dioxide $\left(\mathrm{SO}_{2}\right)$. While the researchers measured the lead memory from the engine's tailpipes, they simultaneously used the EMS 5001 emissions analyzer to investigate the engine's emission releases while using 100SF and then while using 100LL. Emissions were measured during idle power, takeoff power, and cruise power. The researchers are still conducting scientific analysis on the collected data.
Other independent tests have shown that 100SF has passed FAA detonation standards for detonation, energy, and fuel consumption. For regulatory purposes, 100SF will need to be tested against additional performance measures. Experiments could investigate 100SF's ability to perform with various containments, lubricants, additives, and operational conditions of varying temperatures, and density altitudes. Further testing of 100SF may investigate performance in turbocharged, turboprop, and automotive engines. This testing may include corrosion, volatility, exposure, and degradation investigations.

\section{References}

AeroShell. (2011). Lead Fouling. Retrieved from http://www.shell.com/ home/content/aviation/aeroshell/technical_talk/techart18_30071600. html

Atwood, D. (2009). Full-scale engine detonation and power performance evaluation of Swift Enterprises 702 fuel (DOT/FAA/AR-08/53). Springfield, VA.

Cline, A. (2000, January). Engine Basics: Detonation and Pre-Ignition. Contact Magazine, 54 Retrieved from http://www.contactmagazine. com/Issue54/EngineBasics.html

Environmental Protection Agency. (2011) Lead in Air. Retrieved from http://epa.gov/airquality/lead/health.html

Environmental Protection Agency. (2010). Advance notice of proposed rulemaking on lead emissions from piston-engine aircraft using leaded aviation gasoline: Regulatory announcement (EPA420-F-10-013). Retrieved from http://www.epa.gov/nonroad/aviation/420f10013.htm

Harvey, A. D. (2006). Air records and war flying. Air Power History, 53(3), 35-39.

Loyola University of Chicago. (2011). Experiment 9: Direct titration of lead with ErioT and EDTA. Retrieved from http://www.luc.edu/faculty/ afitch/Lead_files/Experiment\%209.pdf

Matsui, A. (2007). Case study: Switch to unleaded gas. PBS Newshour. Retrieved from http://www.pbs.org/newshour/indepth_coverage/ science/alt_fuels/unleaded.html

Midgley T. (1937). From the periodic table to production. Industrial and Engineering Chemistry, 29(2), 41-44, doi: 10.1021/ie50326a032.

Sargent, S. (2008). Swift Enterprises hopes to take off with renewable aviation gas. Medill Reports-Chicago, Northwestern University. Retrieved from http://news.medill.northwestern.edu/chicago/news. aspx $? \mathrm{id}=97989$

Schaufele, R. D. (2008). FAA aerospace forecast. Washington, DC. Retrieved from Federal Aviation Administration website: http://www. faa.gov/data_research/aviation/aerospace_forecasts/2009-2025/media/ 2009\%20Forecast\%20Doc.pdf

U.S. Department of Health and Human Services, Agency for Toxic and Substances Disease Registry. (2007). ToxFAQs for lead (CAS \# 743992-1). Retrieved from http://www.atsdr.cdc.gov/tfacts13.pdf

Windom, B. C., Lovestead, T. M., \& Bruno, T. J. (2010). Application of the advanced distillation curve method to the development of unleaded aviation gasoline. Energy Fuels, 24(5), 3275-3284. doi: 10.1021/ ef100178e 